\title{
Optimal Debt Management with a Stability and Growth Pact
}

\author{
Alessandro Missale*- Università di Firenze
}

First Version: March 8, 2000

\begin{abstract}
The "Stability and Growth Pact" introduces deficit stabilization as a new interesting objective of debt management. The interest payments on public debt may serve as an important buffer against the budget consequences of cyclical downturns and unexpected deflation. The optimal debt composition depends on the correlations between interest rates, output and inflation. Estimated correlations for the period 1960-1998 and the implied debt compositions provide benchmarks for implications regarding the EMU. The paper explores how relevant correlations between output, inflation and interest rates may have changed with the shift in the monetary policy regime and thus how the debt composition, which stabilizes the deficit, has changed. A longer maturity structure of conventional debt is optimal if the ECB places a lower weight on output stabilization than the national monetary authorities and if EMU member states are hit by asymmetric shocks. Short term conventional debt should instead be issued by countries which experience a relatively higher output and inflation uncertainty and a lower sensitivity of aggregate demand to interest-rate changes. The optimal share of inflation-indexed debt is largest in a strict inflation targeting regime; the lower the weight that the ECB assigns to output stabilization, the more attractive is inflation indexation for deficit stabilization.
\end{abstract}

Corresponding Address: Alessandro Missale; Dip. Studi sullo Stato; Via S. Caterina d'Alessandria 3; 50129 Firenze; Italy. Tel. +39-055-4622920 Fax +39-055-472102. E-mail: missale@unifi.it

*I thank Carlo Favero and Riccardo Rovelli for insigthful discussion on monetary policy. This version of the paper also benefited from comments of seminar participants to the Macro-seminar at the Department of Economics of the Università di Bologna. All errors are mine. 


\section{Introduction}

This paper examines how the public debt should be managed to minimize the risk that the budget deficit exceeds the 3\% limit of the Stability and Growth Pact. This requires to choose debt instruments which provide flexibility to fiscal policy; which create room in the budget for the automatic stabilizers or counter-cyclical fiscal policy to operate. The idea is that the maturity and the indexation of public debt can be used to hedge against inflation and output shocks to the budget, so as to stabilize the deficit-to-GDP ratio. The optimal debt composition would depend on the correlations between output, inflation and interest rates. For instance, if interest rates and output are negatively correlated, then a long maturity debt would insulate the government budget from interest rate shocks, thus avoiding higher than expected interest payments at times of cyclical downturns. The choice of indexation of public bonds to the inflation rate or to GDP can also be examined within this framework. For instance, inflation-indexed debt could be a useful hedge since deflation worsens the budget as a consequence of several nominalistic features of the tax system and spending programs.

The idea of the paper follows from the optimal taxation literature on debt management stemming from Lucas and Stokey (1983), extended by Bohn $(1988,1990)$ and Barro (1995) and reviewed in Missale (1997). The main insight of this literature, that debt instruments provide insurance against macroeconomic shocks to the budget, and thus allow to smooth taxes across time and states of nature, is applied here to a situation where the constraint imposed by the Stability and Growth Pact induces a greater attention to insuring against current unfavorable events as opposed to tax-smoothing over the future ahead. Specifically, the Pact introduces deficit stabilization (or deficit smoothing) as a new objective of debt management. This is formalized by a simple three-period model where the government trades off the cost of exceeding the $3 \%$ deficit limit against the costs of fiscal correction. The budget is affected by cyclical conditions, namely by output and inflation, while an increase in interest rates leads to higher debt servicing costs on the part of the debt which has a short maturity. The government chooses between short and long-term conventional debt and on inflation-indexed debt, before any shock realizes, while it decides the fiscal correction after observing output, inflation and the interest rate. However, the effect of fiscal policy remains uncertain since the budget is hit by a random shock.

The optimal debt composition stabilizes the deficit-to-GDP ratio and it depends on the correlations between interest rates, output and inflation (and on the elasticities of the deficit to inflation and output). For the period preceding the EMU the relevant conditional covariances can be estimated for each member state by simple regressions. These covariances allow to derive the debt composition that would be optimal for deficit stabilization if monetary policy were carried out at the national level; i.e. before the advent of EMU. The estimated relations with the implied debt compositions 
provide benchmarks for implications regarding the EMU. Since empirical analysis is unfeasible for this purpose, a simple multi-country model is presented where the European Central Bank (ECB) reacts to the harmonized CPI index and output gaps of member states. The model comprises a supply equation and an aggregate demand equation for each country, but one interest-rate reaction function to average EMU inflation and output gap. In this way the relevant correlations can be related to local supply and demand shocks and the responses of the ECB to such shocks. The analysis explores how the correlations of the interest rate with local output and inflation may have changed because of the loss of monetary policy autonomy by the single countries. This allows to make inferences on how the composition of the debt, which is optimal for deficit stabilization, has changed with the advent of EMU and thus derive policy implications for an efficient management of the public debt.

The move from national monetary policy to EMU does modify the debt composition which is optimal for deficit stabilization depending on the preferences of the ECB, on the correlation of supply and demand shocks across EMU member states, on differences in the size of such shocks and in the transmission mechanism of monetary policy. A longer maturity structure of conventional debt is optimal if the ECB assigns less weight on output stabilization (relative to inflation stabilization) than the national monetary authorities and if EMU member states are hit by asymmetric shocks. Short term conventional debt should instead be issued by countries which experience a relatively higher output and inflation uncertainty and present a lower sensitivity of aggregate demand to interest-rate changes. The optimal share of inflation-indexed debt is largest in a strict inflation targeting regime; the lower the weight on output stabilization the more attractive is inflation indexation for deficit stabilization.

\section{The government objective}

The "Stability and Growth Pact" introduces deficit smoothing as a new interesting objective of debt management. Indeed, in the transition path from still high structural deficits to a steady state of balanced budgets, the interest payments on public debt may serve as an important buffer against unexpected cyclical downturns. For instance lower than expected interest rate and thus interest payments on short maturity debt can offset the budget consequences of an unanticipated slowdown of economic activity.

While smoothing the budget deficit over time is clearly the optimal policy to avoid the penalties associated with the violation of the $3 \%$ deficit limit, we argue that deficit smoothing across states of nature is also optimal and it suggests a new important role for debt management. To do so, we sketch a simple model of fiscal correction which motivates the objective of minimizing the uncertainty affecting the deficit-to-GDP ratio. The idea is that as we consider bad shocks of larger size the probability that they occur is lower. This makes the government unwilling to expose 
the budget under its control to further unnecessary uncertainty, since any increase in the controlled component of the deficit would raise the probability of exceeding the $3 \%$ limit by more than a deficit reduction (of the same size) would reduce it.

Therefore, when the fiscal authority chooses debt instruments it must take into consideration the stochastic relations between output, inflation and interest rates. We assume that the latter variables are affected by monetary policy but not by fiscal policy. The model is therefore admittedly simple in that it entails a complete separation of fiscal and monetary policy and does not allow for the joint determination of output and inflation that would certainly be desirable.

The time-horizon extends over three periods. In period $t-1$ the government decides the debt composition; i.e. the relative amounts of one-period conventional bonds, two-period conventional bonds and two-period inflation-indexed bonds. Then, in period $t$, the monetary authority sets the interest rate as a reaction to inflationary pressure from macroeconomic shocks. This determines the interest rate at which the short-term debt is refinanced and hence the interest payments on such debt at time $t+1$. This interest rate along with new shocks affects the output gap and the inflation rate in period $t+1$ and thus the cyclical component of the budget and the interest payments on inflation-indexed debt. The fiscal correction aimed at containing the deficit within the $3 \%$ limit is implemented in period $t+1$ after the government observes the realization of output and inflation. However, the outcome of government's efforts is uncertain, since it also depends on a random shock to the budget at the end of period $t+1$.

In this section we focus on the government's decisions given output, inflation and the interest rate. This allows us to derive the optimal debt composition as a function of the stochastic relations between output, inflation and the interest rate. Then, in the next sections, we examine how such variables are determined by monetary policy.

The government wants to maintain the deficit-to-GDP ratio below the $3 \%$ limit, that is, below a given budget deficit $D^{T}$. In order to reach this objective the government controls the deterministic component of the budget. Assuming that efforts to cut the deficit are increasingly costly the government loss is given by

$$
L_{t+1}=p K+\frac{1}{2} F_{t+1}^{2}
$$

where $p$ is the probability of exceeding $D^{T}$, i.e. the $3 \%$ deficit limit, and $K$ is the fixed cost of failure. ${ }^{1}$ Finally, $F$ denotes the fiscal correction (relative to GDP) that is enacted by the government.

The outcome of the government's efforts is uncertain because the budget is subject to random shocks which occur after taxes and spending, $F_{t+1}$, have been set. Defining

\footnotetext{
${ }^{1}$ Actually, the amount that the government must place in a deposit bearing no interest increases with the excess deficit. By contrast, reputational costs which are also relevant are of a fixed nature.
} 
with $X$ the shock to the budget, the probability, $p$ of exceeding the deficit limit, $D^{T}$, is equal to

$$
p=\operatorname{Prob}\left[X+G_{t+1}-F_{t+1}>D^{T}\right]=\operatorname{Prob}\left[X>D^{T}+F_{t+1}-G_{t+1}\right]
$$

where $G_{t+1}$ is the deficit-to-GDP ratio in the absence of government intervention, that is, the trend component of the deficit which is affected by cyclical conditions, i.e. by output and inflation, as follows

$$
G_{t+1}=g-\eta_{y} y_{t+1}-\eta_{\pi} \pi_{t+1}+R_{t+1} b
$$

where $g$ is the deterministic component of the deficit, $y_{t+1}$ is the output gap, $\pi_{t+1}$ is the rate of inflation, $\eta_{y}$ is the output elasticity of the government budget, $\eta_{\pi}$ is the inflation elasticity of the budget and $R_{t+1} b$ is the flow of interest payments (relative to GDP) on the debt $b$.

The deficit-to-GDP ratio is affected by cyclcal conditions, i.e. by the output gap $y_{t+1}$ and by the rate of inflation $\pi_{t+1}$. While the impact of economic activity on the budget is well known from a number of studies (see e.g. Giorno et al. 1995), inflation also helps to reduce the deficit because tax systems and spending programs are not fully indexed (besides interest payments). Table 1 taken from Giorno et al. (1995) reports the effects on structural budget balances of EU countries of an increase in the output gap by one percentage point. With the notable exceptions of Greece, Portugal and Sweden, OECD countries have elasticities in the 0.5 to 0.6 range. The effects of inflation on government budgets have not been studied and measured to the same extent, but for the few countries where estimates are available, they appear substantial. For instance, Persson, Persson and Svensson (1998) estimate that for Sweden an increase of one percentage point of the inflation rate leads to a budget improvement of $0.4 \%$ of GDP on a yearly basis.

The flow of interest payments, $R_{t+1} b$, on the outstanding debt depends on the interest rates and on the composition of public debt as determined by past debt management decisions. To derive the interest payments in period $t+1$ we use the fact that the interest rate, $i_{t-1}$ prevailing in period $t$ is set in period $t-1$ and is thus known at the time of debt issuance. Since we are interested in the relative cost of alternative funding instruments, the exact level of such rate is irrelevant and is thus assumed equal to zero, -i.e. $i_{t-1}=0$-, to simplify the notation.

Then, denoting with $E_{t-1}$ the expectations conditional on the information available at period $t-1$, the interest payments relative to GDP in period $t+1$ are equal to

$$
R_{t+1} b=(1-s-x) b E_{t-1} i_{t}+s b i_{t}+x b\left[E_{t-1}\left(i_{t}-\pi_{t+1}\right)+\pi_{t+1}\right]
$$

where $s$ is the share of one-period conventional bonds and $\mathrm{x}$ is the share of inflationindexed bonds, both issued in period $t-1$. The interest payments in period $t+1$ on one-period bonds depend on the nominal interest rate, $i_{t}$, set at the end of period $t$ 
and prevailing in period $t+1$. The payments on inflation-indexed bonds depend on the inflation rate, $\pi_{t+1}$, between period $t$ and $t+1$.

An important role in the choice of debt maturity is thus played by the interest rate, $i_{t}$, relative to its expectation at period $t-1$. Indeed, the nominal cost of shortterm debt is determined by the interest rate, $i_{t}$, at which the debt is refinanced. On the other hand, the nominal cost of long-term debt is (pre)determined in period $t-1$; it depends on the expectations of $i_{t}$, that is, on the forward rate $E_{t-1} i_{t}$.

Finally, it is worth noting that we consider nominal as opposed to real interest payments, that is, we do not deflate $R b$ by nominal output growth. The justification is that the effect of output growth and thus inflation are arguably small; i.e. smaller than the direct effect on the other components of the deficit. For example, even if the interest expenditure were as large as $5 \%$ of GDP, an increase in nominal output growth from $4 \%$ to $10 \%$ would lead to a deficit reduction smaller than $0.03 \%$ of GDP. This should be compared with a deficit reduction of $1.5 \%$ of GDP for a $3 \%$ real output growth or for a fall in interest rate of 300 basis points.

The time-horizon extends over three periods. In period $t-1$ the government decides the debt composition; i.e. the relative amounts of one-period conventional bonds, two-period conventional bonds and two-period inflation-indexed bonds. Then, in period $t$, the monetary authority sets the interest rate as a reaction to inflationary pressure from macroeconomic shocks. This determines the interest rate at which the short-term debt is refinanced and hence the interest payments on such debt at time $t+1$.

The sequence of events is as follows. In period $t-1$, the government decides the relative amounts of inflation-indexed bonds, two-period conventional bonds, and one-period conventional bonds maturing at the end of period $t$. When the debt composition is chosen, the one-period interest rate prevailing in period $t$ is known (for the ease of notation we have assumed the real interest rate equal to zero). Private investors must form expectations about the one-period interest rate, $i_{t}$, which will prevail in period $t+1$. This interest rate is uncertain since it depends on the reaction of the central bank to the inflationary pressure from macroeconomic shocks. The monetary authority sets the interest rate $i_{t}$ in period $t$, before the debt is refinanced. This rate thus determines the interest payments in period $t+1$ on conventional short term debt and affects output and inflation of period $t+1$. Finally, in period $t+1$ the government decides the fiscal correction after observing output and inflation but before the shocks to the budget, $X$, realizes. Therefore, a large exogenous shock, $X$, hitting the budget at the end of period $t+1$, can make the deficit exceed the $3 \%$ limit, $D^{T}$. 


\section{The choice of debt maturity}

In this section we examine the choice of taxes and debt maturity by solving the government problem backward. We first derive the choice of taxes for a given debt composition, output, inflation and the interest rate. We then characterize the choice of debt maturity and debt indexation as a function of the stochastic relations between output, inflation and the interest rate.

The government decides the fiscal correction facing a trade off between the cost of the correction and the probability of incurring in the penalties set by the Stability and Growth Pact when the $3 \%$ deficit limit is exceeded. ${ }^{2}$

The government minimizes the loss function (1) subject to the probability defined in (2). To derive such probability, we assume that the distribution of the shock $X$ is triangular with mean zero, $E_{t+1} X=0$, and a support ranging between $-A$ and $A .^{3}$ We consider the choice of taxes by a government that is expected to be successful in the sense that for the average shock $E_{t+1} X=0$, the expected budget shows a deficit lower than $D^{T}$; i.e. $G_{t+1}-F_{t+1}<D^{T}$. This government fails only if hit by a "large" realization of $X$. For such a government, the probability of exceeding the $3 \%$ deficit limit is equal to

$$
p=\operatorname{Prob}\left[X>F_{t+1}-G_{t+1}+D^{T}\right]=\frac{1}{2 A^{2}}\left(A+G_{t+1}-D^{T}-F_{t+1}\right)^{2}
$$

where such probability has been obtained by substituting $G_{t+1}-D^{T}-F_{t+1}$ in the right-hand side of the triangular distribution of $X$.

Replacing $p$ in the government loss function (1) we obtain the loss that the government expects before knowing the realization of $X$, but after observing output, inflation, the interest rate $i_{t}$, and thus the interest payments on the public debt.

$$
L_{t+1}=\frac{K}{2 A^{2}}\left(A+G_{t+1}-D^{T}-F_{t+1}\right)^{2}+\frac{1}{2} F_{t+1}^{2}
$$

Therefore, the analysis is kept simple by assuming that the uncertainty about output, inflation and interest rates is fully resolved at the time the government decides the fiscal correction. Equation (4) also makes clear that the problem is relevant only insofar as the maximum shock $A$ is greater than the difference between the $3 \%$ deficit limit and the expected deficit. The Stability and Growth Pact will not guide the choice of debt instruments when governments will run sufficient structural budget surpluses.

Deriving $L_{t+1}$ with respect to $F_{t+1}$, we obtain:

$$
F_{t+1}^{*}=\delta\left(A+G_{t+1}-D^{T}\right) \quad \text { where } \quad 0<\delta \equiv \frac{K}{A^{2}+K}<1
$$

\footnotetext{
${ }^{2}$ The costs of the correction are likely to involve a loss of output which is not explicitly modelled.

${ }^{3}$ As it will become clear later on, only the algebra, but not the substance, of our results changes if the distribution of $X$ were not truncated, for example if $X$ were normally distributed.
} 
The optimal level of the fiscal correction $F_{t+1}$ is an increasing function of the trend deficit $G_{t+1}$.

Now consider the choice of the maturity of conventional debt and indexation. Substituting $F_{t+1}^{*}$ in the loss function (4) and taking expectations conditional on the information at time $t-1$, yields the expected value of the government loss at the time when the government decides the debt composition. The expected loss is equal to

$$
E_{t-1} L_{t+1}^{*}=E_{t-1} \frac{\delta}{2}\left[A+G_{t+1}-D^{T}\right]^{2}
$$

and is an increasing and convex function of the trend deficit

$$
G_{t+1}=g-\eta_{y} y_{t+1}-\eta_{t+1} \pi_{t+1}+(1-s-x) b E_{t-1} i_{t}+s b i_{t}+x b\left[E_{t-1}\left(i_{t}-\pi_{t+1}\right)+\pi_{t+1}\right]
$$

Since we have assumed risk neutral investors, the expected cost of debt servicing is independent of the maturity chosen at the beginning of period $t-1$, -i.e. $\quad E_{t-1} R_{t+1}=$ $E_{t-1} i_{t}-{ }^{4}$ However, the choice of debt maturity is not irrelevant. Since $L_{t+1}^{*}$ is a convex function of the deficit, the expected loss is minimized by reducing the volatility of the deficit-to-GDP ratio.

Therefore, the government should choose the debt composition that supports deficit smoothing across states of nature. The reason is that any increase in the trend deficit raises the probability of exceeding the $3 \%$ limit by a larger amount than a decrease of the deficit reduces it. This is because, the likelihood of bad shocks to the budget decreases as increasingly larger shocks are considered. ${ }^{5}$ Put it simply, the government - because on average is successful - is unwilling to take bets: it chooses the debt instruments which offer the best insurance against the negative consequences of cyclical downturns.

The optimal shares of short-term conventional debt, $s^{*}$, and long-term inflationindexed debt $x^{*}$ which minimize the government expected loss (5) are equal to

$$
\begin{gathered}
s^{*}=\frac{\eta_{y}}{b} \frac{\operatorname{Cov}\left(y_{t+1} i_{t}\right)}{\operatorname{Var}\left(i_{t}\right)}+\frac{\eta_{\pi}}{b} \frac{\operatorname{Cov}\left(\pi_{t+1} i_{t}\right)}{\operatorname{Var}\left(i_{t}\right)}-x \frac{\operatorname{Cov}\left(\pi_{t+1} i_{t}\right)}{\operatorname{Var}\left(i_{t}\right)} \\
x^{*}=\frac{\eta_{y}}{b} \frac{\operatorname{Cov}\left(y_{t+1} \pi_{t+1}\right)}{\operatorname{Var}\left(\pi_{t+1}\right)}+\frac{\eta_{\pi}}{b}-s \frac{\operatorname{Cov}\left(\pi_{t+1} i_{t}\right)}{\operatorname{Var}\left(\pi_{t+1}\right)}
\end{gathered}
$$

where $\operatorname{Var}($.$) and \operatorname{Cov}($.$) denote variances and covariances conditional on the infor-$ mation available at time $t-1$.

Equation (6) shows that short term debt is optimal when the interest rate and thus interest payments are positively correlated with unanticipated inflation and economic

\footnotetext{
${ }^{4}$ Although debt servicing costs are trivially minimized by any choice of debt maturity and/or indexation, the model can straightforwardly be extended to consider cost motivations, say, by adding a liquidity or a risk premium to the cost of any type of debt.

${ }^{5}$ This is to say that, in the region we are considering, the probability density function is downward sloping.
} 
activity. Put it simply, it is optimal for the government to pay lower interests at times when output and inflation are lower than expected and the primary deficit is unexpectedly high. On the other hand, the benefits of short-term debt are clearly reduced by a higher variance of the interest rate, since independent variations of the interest rate produce unnecessary fluctuations in interest payments. Except for the role of inflation, the implications for debt management are interestingly similar to those arising from tax-smoothing motivations (see e.g. Bohn 1990, Barro 1995 and Missale 1997).

Equation (6) shows that the optimal share of inflation indexed debt increases with the covariance between output and inflation. If this covariance is positive inflationindexed debt provides an insurance against unexpected slowdowns in economic activity, since lower interest payments on such debt partly offset the cyclical deficit. Inflation-indexed debt becomes however less attractive as the conditional variance of inflation increases. Implications of deficit smoothing are again strikingly similar to implications from tax-smoothing (see e.g. Bohn 1988,1990) Equation (6) also points out that issuing inflation-indexed debt is optimal even when the covariance between output and inflation is zero. The reason is that we consider the positive impact of inflation (when is low) on the primary deficit arising from several nominalistic features of the tax system and spending programs (see Persson, Persson and Svensson 1998). This implies that inflation-indexed debt provides the perfect insurance against unexpected deflation.

While the result that the optimal debt composition relates to the stochastic structure of the economy is not new in the literature, in what follows we take a step further by explictly investigating the role of monetary policy in determining the relations between the macroeconomic variables affecting the government budget.

\section{A simple model of inflation targeting}

The choice between short and long-term conventional debt depends on the stochastic relations between output, inflation and the interest rate as determined by the reaction of the monetary authority to macroeconomic shocks affecting the economy. Moreover, the reaction of the monetary authority and the extent of such a reaction vary depending on the monetary policy rule and on the authority's preferences, say, on its degree of conservativeness. Put it simply, we expect the monetary regime to play an important role in the choice of debt maturity. In this section we examine the relation between output, inflation and the short-term interest rate in an inflation targeting regime where monetary policy is run by a national monetary authority. ${ }^{6}$ Although we are interested in the regime where monetary policy is conducted by the

\footnotetext{
${ }^{6}$ See Favero and Rovelli (1999) for a presentation and estimation of the model and a discussion of the monetary policy literature.
} 
European Central Bank (ECB), the analysis of this section provides the benchmark to examine the changes in the relations between output, inflation and the interest rate introduced by the advent of EMU.

The economy is made by an aggregate supply and an aggregate demand. The aggregate demand is given by:

$$
y_{t+1}=\rho y_{t}-a\left[i_{t}-E_{t} \pi_{t+1}-\bar{r}\right]+v_{t+1}
$$

where $E_{t}$ denotes rational expectations conditional on the information available at time $t$, and $\left(i_{t}-E_{t} \pi_{t+1}\right)$ is the real interest rate between period $t$ and $t+1$. Output autocorrelation is denoted by $\rho$. Finally, $v_{t+1}$ is an i.i.d. demand shock with mean zero and variance equal to $\sigma_{v}^{2}$.

The central bank controls aggregate demand and thus output and inflation -with a lag-through the choice of the nominal interest rate, $i_{t}$, at the end of period $t$. The impact of monetary policy on aggregate demand is given by $a$, which measures the effectiveness of monetary policy.

The supply side of the economy is modelled as the following augmented Phillips curve:

$$
\pi_{t+1}=w \pi_{t}+(1-w) E_{t} \pi_{t+1}+c y_{t+1}+u_{t+1}
$$

where $c$ captures real rigidities in the economy; i.e. $c$ measures the impact of the output gap, $y_{t+1}$, on inflation. Inflation is affected by an adverse supply shock $u_{t}$ with mean zero and variance equal to $\sigma_{u}^{2}$.

Equation (9) can be derived from Taylor's $(1979,1980)$ staggering of wage contracts and has recently been used by Fuhrer and Moore (1995). This specification implies important nominal rigidities in that wage contracts last two periods and overlap; the current inflation rate thus depends (by a fraction $w$ ) on wages and prices set in period $t$. More precisely, the inflation rate for period $t+1$ reflects the weighted average of wage contracts set at the beginning of period $t+1$, with weight $(1-w)$, according to the expectations formed at the end of period $t$ and wage contracts set at the beginning of period $t$ with weight $w$. The parameter $w$ thus measures the extent of coordination; the lower $w$ the greater is the number of contracts renewed in period- 1 and thus the faster is the adjustment of the price level to changes in expectations.

The main objective of monetary policy is to maintain price stability, but we also allow for output stabilization as a possible additional concern. The loss of the monetary authority is defined over deviations of the inflation rate, $\pi_{t+i}$, from its target, $\pi^{T}$, and the output gap, $y_{t}$.

$$
L_{t}=\Sigma_{i=1}^{\infty}\left[E_{t}\left(\pi_{t+i}-\pi^{T}\right)^{2}+\lambda E_{t} y_{t+i}^{2}\right]
$$

The weight given by the central bank to output stabilisation relative to the inflation target, is denoted by $\lambda$ and is publicly known. 
The monetary authority sets the short-term interest rate, $i_{t}$, to minimize (10) subject to (8) and (9). This leads to the following interest-rate rule:

$$
i_{t}=\bar{r}+\pi^{T}+\frac{c w+a \lambda w^{2}}{a c^{2}+a \lambda w^{2}}\left(\pi_{t}-\pi^{T}\right)+\frac{\rho}{a} y_{t}
$$

where we must assume that $w-a c>0$ to ensure that an increase in the interest rate has a negative impact on the inflation rate. This also implies that the nominal interest rate reaction to current inflation is greater than one. As expected, the reaction to current inflation is stronger the lower is the weight, $\lambda$, assigned to output stabilization. Finally, it is worth noting that the effect of nominal and real rigidities is ambiguous. Lower real rigidities - a higher $c$ - may reduce the need to react to inflationary pressure if $c^{2}>\lambda w(w-2 a c)$. The same condition ensures that more nominal rigidities, $-\mathrm{a}$ higher $w$ - leads to a stronger interest-rate reaction to inflationary pressure.

The effect of monetary policy on debt management can now be investigated by deriving the covariances between output, inflation and the interest rate conditional on the information available at time $t-1$ when the government chooses the composition of the debt. The unanticipated components of inflation, output and the interest rate are as follows:

$$
\begin{gathered}
\pi_{t+1}-E_{t-1} \pi_{t+1}=\frac{\lambda w^{2}}{c^{2}+\lambda w^{2}}\left(\pi_{t}-E_{t-1} \pi_{t}\right)+u_{t+1}+c v_{t+1} \\
y_{t+1}-E_{t-1} y_{t+1}=-\frac{c w}{c^{2}+\lambda w^{2}}\left(\pi_{t}-E_{t-1} \pi_{t}\right)+v_{t+1} \\
i_{t}-E_{t-1} i_{t}=\frac{c w+a \lambda w^{2}}{a c^{2}+a \lambda w^{2}}\left(\pi_{t}-E_{t-1} \pi_{t}\right)+\frac{\rho}{a}\left(y_{t}-E_{t-1} y_{t}\right)
\end{gathered}
$$

Then, defining

$$
z=\frac{w}{c^{2}+\lambda w^{2}}
$$

the variances and covariances conditional on the information available at time $t-1$, when funding instruments are chosen, are equal to

$$
\begin{aligned}
\operatorname{Cov}\left(\pi_{t+1} i_{t}\right) & =(z / a) \rho \lambda w \operatorname{Cov}\left(y_{t} \pi_{t}\right)+\left(z^{2} / a\right) \lambda w[c+a \lambda w] \operatorname{Var}\left(\pi_{t}\right) \\
\operatorname{Cov}\left(y_{t+1} i_{t}\right) & =-(z / a) \operatorname{co} \operatorname{Cov}\left(y_{t} \pi_{t}\right)-\left(z^{2} / a\right) c[c+a \lambda w] \operatorname{Var}\left(\pi_{t}\right) \\
\operatorname{Cov}\left(\pi_{t+1} y_{t+1}\right) & =c \sigma_{v}^{2}-z^{2} c \lambda w \operatorname{Var}\left(\pi_{t}\right) \\
\operatorname{Var}\left(\pi_{t+1}\right) & =c^{2} \sigma_{v}^{2}+\sigma_{u}^{2}+z^{2} \lambda^{2} w^{2} \operatorname{Var}\left(\pi_{t}\right) \\
\operatorname{Var}\left(i_{t}\right) & =(\rho / a)^{2} \operatorname{Var}\left(y_{t}\right)+\left(\rho z / a^{2}\right)[c+a \lambda w] \operatorname{Cov}\left(y_{t} \pi_{t}\right)+ \\
& +(z / a)^{2}[c+a \lambda w]^{2} \operatorname{Var}\left(\pi_{t}\right)
\end{aligned}
$$


where

$$
\begin{aligned}
\operatorname{Cov}\left(y_{t} \pi_{t}\right) & =c \sigma_{v}^{2} \\
\operatorname{Var}\left(y_{t}\right) & =\sigma_{v}^{2} \\
\operatorname{Var}\left(\pi_{t}\right) & =c^{2} \sigma_{v}^{2}+\sigma_{u}^{2}
\end{aligned}
$$

Then, the coefficients of the equations (6) and (7) are equal to

$$
\frac{\operatorname{Cov}\left(\pi_{t+1} i_{t}\right)}{\operatorname{Var}\left(i_{t}\right)}=\frac{a z \lambda w\left\{\rho \operatorname{Cov}\left(y_{t} \pi_{t}\right)+z[c+a \lambda w] \operatorname{Var}\left(\pi_{t}\right)\right\}}{\rho^{2} \operatorname{Var}\left(y_{t}\right)+z[c+a \lambda w]\left\{\rho \operatorname{Cov}\left(y_{t} \pi_{t}\right)+z[c+a \lambda w] \operatorname{Var}\left(\pi_{t}\right)\right\}}
$$

which is non-negative, increases with $\lambda$ and is equal to zero for $\lambda=0$.

$$
\frac{\operatorname{Cov}\left(y_{t+1} i_{t}\right)}{\operatorname{Var}\left(i_{t}\right)}=-\frac{z a c\left\{\rho \operatorname{Cov}\left(y_{t} \pi_{t}\right)+z[c+a \lambda w] \operatorname{Var}\left(\pi_{t}\right)\right\}}{\rho^{2} \operatorname{Var}\left(y_{t}\right)+z[c+a \lambda w]\left\{\rho \operatorname{Cov}\left(y_{t} \pi_{t}\right)+z[c+a \lambda w] \operatorname{Var}\left(\pi_{t}\right)\right\}}
$$

which is negative and increases with $\lambda$.

$$
\frac{\operatorname{Cov}\left(\pi_{t+1} y_{t+1}\right)}{\operatorname{Var}\left(\pi_{t+1}\right)}=\frac{c \sigma_{v}^{2}-c z^{2} \lambda w \operatorname{Var}\left(\pi_{t}\right)}{c^{2} \sigma_{v}^{2}+\sigma_{u}^{2}+z^{2} \lambda^{2} w^{2} \operatorname{Var}\left(\pi_{t}\right)}
$$

which is positive for $\lambda=0$ and increases with the variance of demand shocks relative to the variance of supply shocks. Moreover the coefficient (17) is positive for any $\lambda$ and decreases with $\lambda$ for $c^{2}(2-w) \sigma_{v}^{2}<w \sigma_{u}^{2}$. When this condition is not satisfied the coefficient becomes negative over an interval of $\lambda$.

The intuition for the sign of the conditional covariances is as follows. In a strict inflation targeting, interest rates are set so as to fully stabilize inflation. Thus, at time $t-1$ inflation is expected to be uncorrelated with any variable at time $t$, otherwise monetary policy would have intervened. As the authorities care about output stabilization, the interest rate is not raised enough to eliminate inflation and a positive covariance between inflation and the interest rate emerges. The covariance between the output gap and the interest rate is instead always negative since interest rates always act through a reduction of aggregate demand and thus output. This negative correlation is mitigated in a flexible inflation targeting (i.e. for $\lambda>0$ ), because of the weaker reaction of the interest rate to inflationary pressure. The covariance between output and inflation at time $t+1$ conditional on the information at time $t-1$ is uncertain because it depends on both demand and supply shocks occurring at time $t+1$ and by the correlation induced by monetary policy. Contemporaneous shocks leads to a positive covariance while the effect of monetary policy depends on the weight assigned to output stabilization. In a strict inflation targeting the latter effect vanishes while in a flexible inflation targeting such a covariance is negative and 
decreasing with the weight, $\lambda$, assigned to output stabilization (for sufficiently low $\lambda)$.

Therefore, the analysis offers interesting insight for debt management. It suggests that short term debt should not be issued in a strict inflation targeting for the purpose of smoothing the budget deficit. When the monetary authority only cares about price stability, the debt should either have a long maturity or be indexed to the inflation rate. As implied by tax-smoothing, the optimal share of indexed debt increases with the variance of demand relative to supply shocks.

On the contrary, a concern for output stabilization unambiguously favors short term debt since it induces a positive covariance between inflation and the interest rate and increases the covariance between output and the interest rate (though the latter covariance remains negative). Interestingly, a greater concern for output stabilization also reduces the opportunity to issue inflation-indexed bonds. This happens for two reasons. First the variance of inflation rises. Secondly, the (positive) covariance between output and inflation decreases, as the authorities give up inflation stability in exchange for a lower output fall.

\section{The empirical evidence}

In principle, the optimal debt composition for deficit smoothing can be obtained by estimating the conditional covariances of output, inflation and the interest rate. However, past information on the relations between such variables may not be indicative for future debt policy in the EMU. Indeed, in the EMU relevant correlations will differ because of the change in regime from national to supranational monetary policy and because of possible differences between the preferences of the ECB and the local authorities. As little evidence is available for the new regime, we proceed as follows. In this section we estimate the conditional covariances for the period before the EMU while in the next sections we analyze how theoretical covariances and thus the optimal debt composition may have changed in the new regime.

The ratios of conditional covariances and variances can be obtained in two steps. First, the unanticipated components of output, inflation and the interest rate can be estimated as the residuals of forecasting regressions in their (second) lags. Secondly, the relevant ratios between covariances and variances can be obtained as the coefficients of the regressions of the residuals of output and inflation on the residuals of the interest rate and as the coefficients of the regression of the residual of output on the residual of inflation.

Insert Tables 2, 3, 4, 5 


\section{EMU - supranational monetary policy}

To explore how relevant correlations of output, inflation and the interest rate may have changed in the EMU we present a simple model of the domestic economy and the group of other EMU member states where the ECB reacts to the average output gap and average inflation, say, the harmonized CPI index.

Consider two groups of countries - i.e. the domestic country and the other EMU member states - with relative weights in the ECB's loss function equal to $q<0.5$ and $(1-q)>0.5$, respectively. In the open economy aggregate demand and supply are still characterized by equations (8) and (9). The two groups of countries possibly differ for size, variance of shocks and parameter values. The approach is the same as in Leichter and Walsh (1999), but we do not consider interactions; in particular, the impact of EMU output on the demand of the domestic economy is disregarded.

The monetary policy is run by the ECB which chooses the interest rate to minimize

$$
L_{t}^{E C B}=\Sigma_{i=1}^{\infty}\left[E_{t}\left(q \pi_{t+i}+(1-q) \pi_{t+i}^{*}-\pi^{T}\right)^{2}+\lambda E_{t}\left(q y_{t+i}^{2}+(1-q) y_{t+i}^{* 2}\right]\right.
$$

where a "star" indicates a variable of the group "other EMU member states".

The interest rate rule in the open economy is equal to

$$
\begin{aligned}
i_{t} & =\bar{r}+\pi^{T}+\frac{P\left(Q+Q^{*}\right)+a \lambda P\left(P+P^{*}\right)}{a\left(Q+Q^{*}\right)^{2}+a \lambda\left(P+P^{*}\right)^{2}}\left(\pi_{t}-\pi^{T}\right)+\frac{Q\left(Q+Q^{*}\right)+\lambda P\left(P+P^{*}\right)}{a\left(Q+Q^{*}\right)^{2}+a \lambda\left(P+P^{*}\right)^{2}} \rho y_{t} \\
& +\frac{P^{*}\left(Q+Q^{*}\right)+a^{*} \lambda P^{*}\left(P+P^{*}\right)}{a^{*}\left(Q+Q^{*}\right)^{2}+a^{*} \lambda\left(P+P^{*}\right)^{2}}\left(\pi_{t}^{*}-\pi^{T}\right)+\frac{Q^{*}\left(Q+Q^{*}\right)+\lambda P^{*}\left(P+P^{*}\right)}{a^{*}\left(Q+Q^{*}\right)^{2}+a^{*} \lambda\left(P+P^{*}\right)^{2}} \rho^{*} y_{t}^{*}
\end{aligned}
$$

where

$$
\begin{aligned}
P & =\frac{q a w}{w-a c} ; & P^{*} & =\frac{(1-q) a^{*} w^{*}}{w^{*}-a^{*} c^{*}} \\
Q & =\frac{q a c}{w-a c} ; & Q^{*} & =\frac{(1-q) a^{*} c^{*}}{w^{*}-a^{*} c^{*}}
\end{aligned}
$$

The interest rate rule (19) can be combined with the aggregate demand (8) and the aggregate supply (9) of the domestic economy in order to derive the conditional covariances between output, inflation and the interest rate. This is done in sections 6.2 to 6.4 where we examine, separately, specific differences in the parameters, shock dimensions and correlations between countries. In the next section we focus on different preferences between the ECB and the national monetary authority over output stabilization. 


\subsection{A conservative ECB}

Although, it was long debated whether the move from the ERM run by the Bundesbank toward a common monetary policy by the ECB might have implied a more accommodating policy, it is by now clear that, because of its strong independence and an exclusive mandate for price stability, the ECB is likely to care little about output stabilization. Then, it is interesting to ask how the optimal choice of debt instruments is affected by a change of the monetary authority that determines a shift toward a less flexible inflation targeting; i.e. to a new regime where less weight is given to output stabilization. To address this issue it is useful to disregard differences among EMU member states and focus on the change in the preferences of the monetary authority; i.e. on a change in $\lambda$. Then, the interest rate rule (19) reduces to equation (11) and the relevant coefficients are the same as those in equations (15), (16), (17); i.e. the same as under a national monetary policy.

Noting that both the coefficients of output on the interest rate and of inflation on the interest rate increase with $\lambda$, while the coefficient of output on inflation decreases in $\lambda$, we reach the following conclusions. If the ECB is more conservative than the national bank, everythingelse being equal, lengthening debt maturity is the optimal policy for EMU participation. Moreover, the share of debt that should be indexed to the inflation rate increases: inflation-indexed debt is more attractive the more conservative is the ECB.

\subsection{Internationally uncorrelated shocks}

The traditional concern with supranational monetary policy is the loss of monetary autonomy to counter asymmetric real shocks. To investigate the implications of internationally uncorrelated shocks for the choice of debt maturity and indexation we assume that EMU economies are hit by supply and demand shocks that are not perfectly correlated -i.e. $\operatorname{Cov}\left(u u^{*}\right)<\sqrt{\operatorname{Var}(u) \operatorname{Var}\left(u^{*}\right)}$ and $\operatorname{Cov}\left(v v^{*}\right)<\sqrt{\operatorname{Var}(v) \operatorname{Var}\left(v^{*}\right)}-$ while we maintain the unrealistic hypotheses that member economies are characterized by the same parameters and are hit by shocks of the same size -i.e. $\operatorname{Var}(v)=$ $\operatorname{Var}\left(v^{*}\right)$ and $\operatorname{Var}(u)=\operatorname{Var}\left(u^{*}\right)$ - .

Assuming that the domestic economy has the same structure as rest of the EMU, unanticipated inflation, output and the interest rate are as follows

$$
\begin{aligned}
\pi_{t+1}-E_{t-1} \pi_{t+1} & =\frac{\lambda w^{2}}{c^{2}+\lambda w^{2}} \hat{\pi}_{t}+u_{t+1}+c v_{t+1}+ \\
& +\frac{(1-q) c}{w-a c}\left[\rho\left(\hat{y}_{t}-\hat{y}_{t}^{*}\right)+\frac{c w+a \lambda w^{2}}{c^{2}+\lambda w^{2}}\left(\hat{\pi}_{t}-\hat{\pi}_{t}^{*}\right)\right]
\end{aligned}
$$




$$
\begin{aligned}
y_{t+1}-E_{t-1} y_{t+1} & =-\frac{c w}{c^{2}+\lambda w^{2}} \hat{\pi}_{t}+v_{t+1}+ \\
& +\frac{(1-q) w}{w-a c}\left[\rho\left(\hat{y}_{t}-\hat{y}_{t}^{*}\right)+\frac{c w+a \lambda w^{2}}{c^{2}+\lambda w^{2}}\left(\hat{\pi}_{t}-\hat{\pi}_{t}^{*}\right)\right] \\
i_{t}-E_{t-1} i_{t} & =\frac{\rho}{a} \hat{y}_{t}+\frac{c w+a \lambda w^{2}}{a c^{2}+a \lambda w^{2}} \hat{\pi}_{t}+ \\
& -\frac{(1-q)}{a}\left[\rho\left(\hat{y}_{t}-\hat{y}_{t}^{*}\right)+\frac{c w+a \lambda w^{2}}{c^{2}+\lambda w^{2}}\left(\hat{\pi}_{t}-\hat{\pi}_{t}^{*}\right)\right]
\end{aligned}
$$

where $\hat{y}_{t}=y_{t}-E_{t-1} y_{t}$, and $\hat{\pi}_{t}=\pi_{t}-E_{t-1} \pi_{t}$

Noting that the assumption that domestic and foreign shocks have the same variance implies that the conditional variances of output and inflation are the same as those of average EMU -i.e. $\operatorname{Var}\left(y_{t}\right)=\operatorname{Var}\left(y_{t}^{*}\right)$ and $\operatorname{Var}\left(\pi_{t}\right)=\operatorname{Var}\left(\pi_{t}^{*}\right)$-, it can be shown that the conditional covariance between inflation and the interest rate is lower in the Monetary Union:

$$
\operatorname{Cov}^{E C B}\left(\pi_{t+1} i_{t}\right)<\operatorname{Cov}\left(\pi_{t+1} i_{t}\right)
$$

This result is not surprising; it captures the fact that the reaction of the interest rate to average EMU inflation tends to be unrelated to domestic inflation when the latter is not triggered by the same Euro shocks (and does not account for more than half of EU inflation). This result holds independently of $\lambda$.

Asymmetric uncorrelated shocks to output and inflation also imply a change in the conditional covariance between output and the interest rate. We find that, if the domestic economy is sufficiently small, the conditional covariance between output and the interest rate falls:

$$
\operatorname{Cov}^{E C B}\left(y_{t+1} i_{t}\right)<\operatorname{Cov}\left(y_{t+1} i_{t}\right)=0 \quad \text { if } q<0.5(a c / w)<0.5
$$

The reason is that changes in interest rates, now triggered by positive foreign demand shocks, have little relation to (good) domestic conditions while they still adversely affects domestic output (notice that output is only affected by demand shocks). However, the economy must be small for its output gap to weigh little in the ECB decisions. This result holds for a higher $q$ as $\lambda$ increases.

Therefore, changes in both covariances due to the asymmetry of shocks appear to suggest that a longer maturity structure is optimal in the new regime for deficit smoothing. However, as shown in equation (6), the optimal share of short-term conventional debt also depends on the variance of the interest rate. The latter is unambiguosly lower in the new regime:

$$
\operatorname{Var}^{E C B}\left(i_{t}\right)<\operatorname{Var}\left(i_{t}\right)
$$


The reason is that the ECB will tend to react less aggressively against shocks that hit only a fraction of EMU member states. Interestingly, the reduction in the volatility of the interest rate with respect to the national monetary policy is stronger the greater the dimension of the country (while still holding $q<0.5$ ). It follows from equation (6), that even in the presence of idiosyncratic shocks, a short maturity structure is less costly if the country is large.

Finally, we examine whether the asymmetry of shocks in a monetary union should favor conventional or inflation-indexed debt. The change in the covariance between output and inflation is ambigous. In particular, it depends on output correlation, $\rho$ and on labor market conditions, i.e. on $w$ and $c$. A sufficient condition for the covariance to increase in the new regime is that the country is small and changes in the interest rate have a weak impact on inflation: ${ }^{7}$

$$
\operatorname{Cov}^{E C B}\left(y_{t+1} \pi_{t+1}\right)>\operatorname{Cov}\left(y_{t+1} \pi_{t+1}\right)=0 \quad \text { if } \quad 2(1-q) w^{2}>w-a c
$$

However, the opportunity to issue inflation-indexed bonds also depends on the conditional variance of inflation. It is easy to show that with internationally uncorrelated shocks the variance of inflation increases in the new regime:

$$
\operatorname{Var}^{E C B}\left(\pi_{t+1}\right)>\operatorname{Var}\left(\pi_{t+1}\right)
$$

It follows that deriving implications for inflation-indexation of uncorrelated shocks is difficult without further informations on the characteristics of the economy.

\subsection{Macroeconomic uncertainty}

So far we have assumed that supply and demand shocks in the domestic economy have the same magnitude as those affecting other EMU member states. An interesting issue is whether and how debt management should change in the EMU when the country considered displays a greater macroeconomic uncertainty. For instance we can think of common Euro shocks displaying a different impact on output and inflation across EMU member states. This can be captured by assuming that

$$
\sigma_{u}^{2} \geq \sigma_{u}^{2 *} \quad \sigma_{v}^{2} \geq \sigma_{v}^{2 *}
$$

In the absence of output concerns - i.e. for $\lambda=0$-, if the magnitude of the shocks, and thus the inflationary pressure, affecting the domestic economy are higher than in the average EMU area, then the covariance between domestic inflation and the interest rate increases since the ECB reaction is not sufficient to eliminate domestic inflation:

\footnotetext{
${ }^{7}$ The higher is $\lambda$ the more likely the covariance in the new regime exceeds the covariance under the national monetary policy.
} 


$$
\operatorname{Cov}^{E C B}\left(\pi_{t+1} i_{t}\right)>\operatorname{Cov}\left(\pi_{t+1} i_{t}\right)=0 \quad \text { if } \quad \lambda=0
$$

and the covariance in the new regime increases with the dimension of the country (while holding $q<0.5$ ) and with the slope, $c$, of the aggregate supply.

On the other hand, if the ECB also cares about output stabilization, then it tends to react too agressively as far as output is concerned from the viewpoint of the domestic economy. As a result, the combined effect on the covariance of inflation and interest rate is ambiguous for $\lambda>0$.

The covariance of output with the interest rate, though it may remain negative, unambiguously increases in the new regime

$$
\operatorname{Cov}^{E C B}\left(y_{t+1} i_{t}\right)>\operatorname{Cov}\left(y_{t+1} i_{t}\right)
$$

This result follows either from a weaker interest-rate reaction to lower EMU inflation uncertainty relative to domestic inflation or from the higher volatility of domestic output for any given interest rate.

Implications for debt management also depend on the variance of the interest rate. When average EMU uncertainty is lower than domestic uncertainty the volatility of short term interest rate is clearly lower in the EMU than with a national monetary policy and the more so the smaller is the country considered.

$$
\operatorname{Var}^{E C B}\left(i_{t}\right)<\operatorname{Var}\left(i_{t}\right)
$$

It follows from equation (6) that a greater macroeconomic uncertainty as that occurring from a higher sensitivity to common Euro shocks should favor short-term over long-term conventional debt. In particular, a shorter maturity is suggested by the positive correlation between the interest rate and inflation which arises when the ECB cares little about output stabilization. The covariance between output and the interest rate is also higher under the common monetary policy, though it may remain negative.

Regarding the opportunity to issue inflation-indexed, the effect of a higher volatility of output and inflation is uncertain. In particular, the covariance between output and inflation may rise or fall relative to the national policy. Focusing on the realistic case of a strict inflation targeting, -i.e. $\lambda=0$-, we observe that in the new regime inflation will no longer be stabilized while demand shocks to output (greater than EMU average shocks) may or may not be reversed by monetary policy. Obviously, with a positive weight on output stabilization, i.e. with $\lambda>0$, it is more likely that such shocks will not be offset thus raising the covariance between output and inflation. A sufficient condition for the covariance to increase, for any $\lambda$, is a sufficiently small country and a strong impact of the interest rate on inflation:

$$
\operatorname{Cov}^{E C B}\left(y_{t+1} \pi_{t+1}\right)>\operatorname{Cov}\left(\pi_{t+1} y_{t+1}\right) \quad \text { if } \quad q w<a c
$$


However, even though the covariance between output and inflation increases, the optimal share of inflation-indexed debt may fall, since a greater uncertainty unambiguously generates a greater inflation volatility relative to the national policy:

$$
\operatorname{Var}^{E C B}\left(\pi_{t+1}\right)>\operatorname{Var}\left(\pi_{t+1}\right)
$$

Hence it is unlikely that in economies characterized by higher output and inflation volatility, inflation-indexed debt should be issued for deficit smoothing. ${ }^{8}$

\subsection{The impact of monetary policy}

The potentially asymmetric effects of monetary policy across member states is an important policy problem in the Monetary Union, a problem that is the focus of a growing literature (see e.g. BIS 1994,1995, Borio 1995, Barran et al. 1997, Dornbusch et al. 1998). Asymmetries may arise either because of different impacts of the interest rate on aggregate demand or because of differences in the transmission mechanisms due to different labor markets and financial structures. In what follows we investigate the implications for debt management of a stronger impact of the interest rate on the aggregate demand of the domestic economy relative to the EMU average.

To capture the different impact of monetary policy we assume that domestic economic activity is more sensitive to interest rates than the EMU average; i.e. we assume that $a>a^{*}$.

The unanticipated component of output, inflation and the interest rate can be derived from equations (12), (13) and the interest rate rule (19). Defining:

$$
H \equiv \frac{\left(a-a^{*}\right)(w-a c)}{a\left(w-a^{*} c\right)+a^{*}(w-a c)}
$$

where $0<H<1$ for $a>a^{*}$

Then, unanticipated inflation, output and the interest rate are equal to

$$
\begin{aligned}
\pi_{t+1}-E_{t-1} \pi_{t+1} & =\frac{\lambda w^{2}}{c^{2}+\lambda w^{2}}\left(\pi_{t}-E_{t-1} \pi_{t}\right)+u_{t+1}+c v_{t+1}+ \\
& -\frac{c H}{w-a c}\left[\rho\left(y_{t}-E_{t-1} y_{t}\right)+\frac{c w}{c^{2}+\lambda w^{2}}\left(\pi_{t}-E_{t-1} \pi_{t}\right)\right] \\
y_{t+1}-E_{t-1} y_{t+1} & =-\frac{c w}{c^{2}+\lambda w^{2}}\left(\pi_{t}-E_{t-1} \pi_{t}\right)+v_{t+1}+ \\
& -\frac{w H}{w-a c}\left[\rho\left(y_{t}-E_{t-1} y_{t}\right)+\frac{c w}{c^{2}+\lambda w^{2}}\left(\pi_{t}-E_{t-1} \pi_{t}\right)\right]
\end{aligned}
$$

\footnotetext{
${ }^{8} \mathrm{~A}$ sufficient condition for a lower share of inflation-indexed debt in the new regime is that $(1-w) c^{2} \sigma_{v}^{2}>w \sigma_{u}^{2}$; i.e. that inflation is not strongly correlated and/or demand shocks are bigger than supply shocks.
} 


$$
\begin{aligned}
i_{t}-E_{t-1} i_{t} & =\frac{\rho}{a}\left(y_{t}-E_{t-1} y_{t}\right)+\frac{c w+a \lambda w^{2}}{a c^{2}+a \lambda w^{2}}\left(\pi_{t}-E_{t-1} \pi_{t}\right)+ \\
& +\frac{H}{a}\left[\rho\left(y_{t}-E_{t-1} y_{t}\right)+\frac{c w}{c^{2}+\lambda w^{2}}\left(\pi_{t}-E_{t-1} \pi_{t}\right)\right]
\end{aligned}
$$

When the domestic economy is more sensitive to interest rate variations than the EMU average, it experiences too much output variation than it is needed to counter inflationary pressure. As the interest rate rises and output falls more than under a national monetary policy, the covariance between output and the interest rate also decreases relative to national policy stance:

$$
\operatorname{Cov}^{E C B}\left(y_{t+1} i_{t}\right)<\operatorname{Cov}\left(y_{t+1} i_{t}\right)
$$

Too high interest rates and unnecessary contraction of economic activity also imply a strong effect on inflation. In particular if the monetary authorities (before and after EMU) placed no weight on output stabilization, then prices would rise below target generating a negative covariance between inflation and the interest rate. While this likely to be the case, an increase in the covariance between inflation and interest rate cannot be excluded if monetary policy is very accommodating. If output stabilization is given so much weight that interest rates are smoothed in spite of inflationary pressure, then a higher interest rate variation (relative to the national policy) might lead to an increase in the covariance of inflation with the interest rate. A sufficient condition for the covariance to decrease is:

$$
\operatorname{Cov}^{E C B}\left(\pi_{t+1} i_{t}\right)<\operatorname{Cov}\left(\pi_{t+1} i_{t}\right) \quad \text { if }(1+H) c^{2}>\lambda w(w-a c)
$$

Finally, the variance of the interest rate is clearly greater than with a national monetary policy:

$$
\operatorname{Var}^{E C B}\left(i_{t}\right)>\operatorname{Var}\left(i_{t}\right)
$$

It follows that the maturity of conventional debt should be lengthened in the new regime by those countries where demand is more sensitive to the interest rate than the EMU average (provided that not too high a weight is placed on output stabilization).

The opportunity to issue inflation-indexed debt depends on the covariance between output and inflation and the variance of inflation. The former is clearly higher in the EMU insofar as the monetary authority is not concerned with output stabilization. In this case a strong negative impact of the interest rate on economic activity would be associated with unanticipated deflation leading to a positive covariance between output and inflation. However, a reduction in the covariance between output and inflation cannot be excluded if the authorities care about output stabilization and the aggregate supply is relatively flat. A sufficient condition for the covariance to increase is: 


$$
\operatorname{Cov}^{E C B}\left(\pi_{t+1} y_{t+1}\right)>\operatorname{Cov}\left(\pi_{t+1} y_{t+1}\right) \quad \text { if } \quad c^{2} w H+(w-a c)\left(c^{2}-\lambda w^{2}\right)>0
$$

The effect on the variance of inflation is also uncertain, since it depends on how strict is inflation targeting. If the authority aims at stabilizing inflation at any output cost, then excessive interest-rate variation would destabilize inflation leading to an increase in the conditional volatility. On the other hand, if the monetary policy is more accommodating, then a stronger impact of the interest rate on the domestic economy might help to stabilize inflation. A sufficient condition for the variance of inflation to increase is:

$$
\operatorname{Var}^{E C B}\left(\pi_{t+1}\right)>\operatorname{Var}\left(\pi_{t+1}\right) \quad \text { if } \quad c^{2} H>2 \lambda w(w-a c)
$$

To conclude, whether a high sensitivity to interest rates makes a case for inflation indexation is uncertain. When we confine attention to the realistic case of a strict inflation targeting, i.e. $\lambda=0$, both the variance of inflation and its covariance with output increase and the overall effect cannot be determined without further information on the parameter values. The optimal share of inflation-indexed debt may increase in the EMU, but this is certain only for a sufficiently high inflation autocorrelation, $w$.

\section{Conclusions}

We have shown that "The stability and Growth Pact" provides a strong motivation for taking deficit-stabilization as a main goal of debt management. The move from national monetary policy to EMU does modify the debt composition which is optimal for deficit stabilization depending on the preferences of the ECB, on the correlation of supply and demand shocks across member states, on differences in the size of such shocks and in the transmission mechanism of monetary policy. A longer maturity structure of conventional debt is optimal if the ECB assigns a lower weight to output stabilization than the national monetary authorities and if EMU member states are hit by asymmetric shocks. Short term debt is useful only if shocks are internationally correlated and generate a higher uncertainty in domestic output and inflation than in other member states. Debt maturity should also be shortened relative to the previous regime in countries where the interest-rate sensitivity of aggregate demand is lower than the EMU average. The optimal share of inflation-indexed debt is largest in a strict inflation targeting regime; the lower the weight that the ECB assigns to output stabilization, the more attractive is inflation indexation for deficit stabilization. 


\section{References}

Barran, F., V. Coudert and B. Mojon (1997), "The Transmission of Monetary Policy in European Countries, in European Monetary Policy, Pinter, London.

Barro, R.J. (1995), "Optimal Debt Management," NBER Working Paper No.5327, October.

Barro, R.J. (1997), "Optimal Management of Indexed and Nominal Debt," NBER Working Paper No.6197, September.

BIS (1994), National Differences in Interest Rate Transmission C.B.393, Basle.

BIS (1995), Financial Structure and the Monetary Policy Transmission C.B.394, Basle.

Bohn, H. (1988), "Why Do We Have Nominal Government Debt?," Journal of Monetary Economics, 21, 127-40.

Bohn, H. (1990), "Tax Smoothing with Financial Instruments," American Economic Review, 80(5), 1217-30.

Borio, C.E.V. (1995), "The Structure of Credit to the Non-Government Sector and the Transmission Mechanism of Monetary Policy: A Cross-Country Comparison," in BIS (1995)

Favero, C. and R. Rovelli (1999), "Modelling and Identifying Central Bank's Preferences," CEPR Discussion Paper No.2178, June.

Fuhrer, J.C. and G.R. Moore (1995), "Inflation Persistence," Quarterly Journal of Economics, Vol.110, pp.127-59.

Giorno, C., P. Richardson, D. Rosevaere and P. Van der Noord (1995), "Potential Output, Output Gaps and Structural Budget Balances," OECD Economic Studies No.24, pp.167-209.

Leichter, J. and C.E. Walsh (1999), "Different Economies, Common Policy: Policy Trade-offs under the ECB, mimeo, University of California, Santa Cruz, April.

Lucas, R.E. and N.L. Stokey (1983), "Optimal Fiscal and Monetary Policy in an Economy Without Capital," Journal of Monetary Economics, 12, 55-94.

Missale, A. (1997) "Managing the Pubic Debt: The Optimal Taxation Approach," Journal of Economic Surveys, 11(3), pp.235-65.

Persson, M., T. Persson and L.E.O. Svensson (1998), "Debt, Cash Flows and Inflation Incentives: A Swedish Example", in G. Calvo and M. King, eds., The Debt Burden and its Consequences for Monetary Policy (pp.28-62), IEA Conference Volume No.118, MacMillan Press. 
Taylor, J.B. (1979), "Staggered Price Setting in a Macro Model," American Economic Review, 69(2), pp.108-13.

Taylor, J.B. (1980), "Aggregate Dynamics and Staggered Contracts," Journal of Political Economics, Vol.88, pp.1-24. 
Table 1: Effect on Structural Budget Balance (as percentage of GDP) caused by 1 percent increase in the Output Gap

\begin{tabular}{|l|c|l|c|}
\hline \hline Austria & 0.5 & Ireland & 0.5 \\
\hline Belgium & 0.6 & Italy & 0.4 \\
\hline Denmark & 0.5 & Netherlands & 0.6 \\
\hline Finland & 0.6 & Portugal & 0.4 \\
\hline France & 0.5 & Spain & 0.6 \\
\hline Germany & 0.5 & Sweden & 0.8 \\
\hline Greece & 0.4 & UK & 0.5 \\
\hline \hline
\end{tabular}


Table 2: Correlation Coefficients Short Term Interest Rate - GDP level

\begin{tabular}{|l|c|c|c|}
\hline \hline & $\frac{\operatorname{Cov}\left(y_{t+1} i_{t}\right)}{\operatorname{Var}\left(i_{t}\right)}$ & $\frac{\operatorname{Cov}\left(\pi_{t+1} i_{t}\right)}{\operatorname{Var}\left(i_{t}\right)}$ & $\frac{\operatorname{Cov}\left(y_{t+1} \pi_{t+1}\right)}{\operatorname{Var}\left(\pi_{t+1}\right)}$ \\
\hline \hline Austria & -0.28 & $0.38^{* *}$ & 0.02 \\
$67-97$ & $(1.32)$ & $(2.35)$ & $(0.07)$ \\
\hline Belgium & -0.07 & $0.59^{* *}$ & 0.07 \\
$60-97$ & $(0.41)$ & $(3.45)$ & $(0.56)$ \\
\hline Finland & -0.33 & $0.63^{* *}$ & -0.16 \\
$70-97$ & $(0.74)$ & $(2.88)$ & $(0.46)$ \\
\hline France & $-0.33^{* *}$ & $0.56^{* *}$ & $-0.47^{* *}$ \\
$70-97$ & $(2.11)$ & $(4.03)$ & $(2.91)$ \\
\hline Germany & -1.23 & $0.49^{* *}$ & -1.49 \\
$60-97$ & $(1.45)$ & $(4.69)$ & $(1.39)$ \\
\hline Greece & -0.28 & $1.06^{* *}$ & $-0.23^{* *}$ \\
$60-97$ & $(1.05$ & $(2.69)$ & $(2.35)$ \\
\hline Ireland & $-1.04^{* *}$ & $0.66^{*}$ & -0.21 \\
$75-97$ & $(4.67)$ & $(2.0)$ & $(1.11)$ \\
\hline Italy & -0.33 & 0.22 & 0.09 \\
$71-97$ & $(1.70)$ & $(1.13)$ & $(0.45)$ \\
\hline Japan & $-0.59^{* *}$ & $0.59^{* *}$ & $-0.29^{*}$ \\
$69-97$ & $(2.64)$ & $(2.20)$ & $(1.85)$ \\
\hline Netherlands & -0.29 & $0.28^{*}$ & 0.07 \\
$60-97$ & $(1.58)$ & $(1.74)$ & $(0.40)$ \\
\hline Portugal & -0.49 & $1.10^{* *}$ & -0.10 \\
$66-97$ & $(1.15)$ & $(2.48)$ & $(0.63)$ \\
\hline UK & $-0.56^{* *}$ & $1.08^{* *}$ & $-0.43^{* *}$ \\
$69-97$ & $(2.42)$ & $(4.03)$ & $(3.60)$ \\
\hline USA & $-0.53^{*}$ & $1.02^{* *}$ & -0.26 \\
$60-97$ & $(1.88)$ & $(4.65)$ & $(1.46)$ \\
\hline \hline
\end{tabular}


Table 3: Correlation Coefficients Short Term Interest Rate - GDP growth

\begin{tabular}{|l|c|c|c|}
\hline \hline & $\frac{\operatorname{Cov}\left(y_{t+1} i_{t}\right)}{\operatorname{Var}\left(i_{t}\right)}$ & $\frac{\operatorname{Cov}\left(\pi_{t+1} i_{t}\right)}{\operatorname{Var}\left(i_{t}\right)}$ & $\frac{\operatorname{Cov}\left(y_{t+1} \pi_{t+1}\right)}{\operatorname{Var}\left(\pi_{t+1}\right)}$ \\
\hline \hline Austria & $-0.43^{* *}$ & 0.12 & -0.03 \\
$67-97$ & $(2.16)$ & $(0.77)$ & $(0.14)$ \\
\hline Belgium & $-0.44^{* *}$ & $0.57^{* *}$ & -0.16 \\
$60-97$ & $(3.20)$ & $(3.71)$ & $(1.17)$ \\
\hline Finland & $-0.63^{* *}$ & 0.31 & 0.14 \\
$70-97$ & $(2.08)$ & $(1.17)$ & $(0.61)$ \\
\hline France & $-0.45^{* *}$ & $0.46^{* *}$ & $-0.42^{* *}$ \\
$70-97$ & $(3.65)$ & $(3.42)$ & $(2.56)$ \\
\hline Germany & $-0.39^{* *}$ & $0.36^{* *}$ & -0.10 \\
$60-97$ & $(2.27)$ & $(3.46)$ & $(0.39)$ \\
\hline Greece & -0.09 & $1.03^{* *}$ & $-0.31^{* *}$ \\
$60-97$ & $(0.42)$ & $(2.40)$ & $(5.37)$ \\
\hline Ireland & $-0.70^{* *}$ & $0.66^{*}$ & -0.15 \\
$75-97$ & $(3.37)$ & $(1.87)$ & $(1.05)$ \\
\hline Italy & $-0.67^{* *}$ & 0.22 & 0.12 \\
$71-97$ & $(4.86)$ & $(1.01)$ & $(0.73)$ \\
\hline Japan & $-0.37^{*}$ & 0.26 & $-0.25^{* *}$ \\
$69-97$ & $(2.05)$ & $(0.88)$ & $(2.18)$ \\
\hline Netherlands & $-0.47^{* *}$ & 0.25 & -0.01 \\
$60-97$ & $(3.67)$ & $(1.60)$ & $(0.07)$ \\
\hline Portugal & -0.41 & $1.13^{* *}$ & $-0.24^{* *}$ \\
$66-97$ & $(1.36)$ & $(2.56)$ & $(2.17)$ \\
\hline UK & $-0.43^{* *}$ & 0.42 & $-0.27^{* *}$ \\
$69-97$ & $(2.85)$ & $(1.44)$ & $(2.73)$ \\
\hline USA & $-0.65^{* *}$ & $0.60^{* *}$ & $-0.32^{* *}$ \\
$60-97$ & $(3.52)$ & $(2.82)$ & $(2.20)$ \\
\hline \hline
\end{tabular}


Table 4: Correlation Coefficients

Long Term Interest Rate - GDP level - 1960-97

\begin{tabular}{|c|c|c|c|}
\hline & $\frac{\operatorname{Cov}\left(y_{t+1} i_{t}\right)}{\operatorname{Var}\left(i_{t}\right)}$ & $\frac{\operatorname{Cov}\left(\pi_{t+1} i_{t}\right)}{\operatorname{Var}\left(i_{t}\right)}$ & $\frac{\operatorname{Cov}\left(y_{t+1} \pi_{t+1}\right)}{\operatorname{Var}\left(\pi_{t+1}\right)}$ \\
\hline Austria & $\begin{array}{c}-0.66 \\
(1.18)\end{array}$ & $\begin{array}{l}-0.82 \\
(2.05)\end{array}$ & $\begin{array}{c}0.21 \\
(0.87)\end{array}$ \\
\hline Belgium & $\begin{array}{l}-0.04 \\
(0.10)\end{array}$ & $\begin{array}{l}1.29^{* *} \\
(3.53)\end{array}$ & $\begin{array}{c}0.07 \\
(0.50)\end{array}$ \\
\hline Denmark & $\begin{array}{c}-0.75^{* *} \\
(2.97)\end{array}$ & $\begin{array}{l}0.72^{* *} \\
(3.80)\end{array}$ & $\begin{array}{c}-0.52^{* *} \\
(2.68)\end{array}$ \\
\hline Finland & $\begin{array}{l}-1.20^{*} \\
(1.71)\end{array}$ & $\begin{array}{c}0.56 \\
(1.04)\end{array}$ & $\begin{array}{c}-0.18 \\
(0.81)\end{array}$ \\
\hline France & $\begin{array}{l}-0.14 \\
(0.46)\end{array}$ & $\begin{array}{l}0.97^{* *} \\
(2.94)\end{array}$ & $\begin{array}{c}0.02 \\
(0.14)\end{array}$ \\
\hline Germany & $\begin{array}{l}-3.60 \\
(1.61)\end{array}$ & $\begin{array}{l}1.26^{* *} \\
(4.72)\end{array}$ & $\begin{array}{l}-1.59 \\
(1.41)\end{array}$ \\
\hline Ireland & $\begin{array}{l}-0.24 \\
(0.53)\end{array}$ & $\begin{array}{l}2.13^{* *} \\
(5.39)\end{array}$ & $\begin{array}{c}0.11 \\
(0.80)\end{array}$ \\
\hline Italy & $\begin{array}{l}-0.40 \\
(1.23)\end{array}$ & $\begin{array}{c}0.47 \\
(1.10)\end{array}$ & $\begin{array}{c}0.18 \\
(1.46)\end{array}$ \\
\hline Japan & $\begin{array}{l}-0.65 \\
(0.96)\end{array}$ & $\begin{array}{c}1.59^{*} \\
(1.98)\end{array}$ & $\begin{array}{c}-0.42^{* *} \\
(3.28)\end{array}$ \\
\hline Netherlands & $\begin{array}{l}-0.66^{*} \\
(1.72)\end{array}$ & $\begin{array}{l}1.05^{* *} \\
(3.33)\end{array}$ & $\begin{array}{l}-0.01 \\
(0.05)\end{array}$ \\
\hline Portugal & $\begin{array}{c}-0.44 \\
(1.15)\end{array}$ & $\begin{array}{c}0.75^{*} \\
(1.78)\end{array}$ & $\begin{array}{c}-0.09 \\
(0.56)\end{array}$ \\
\hline Spain & $\begin{array}{l}-0.20 \\
(0.54)\end{array}$ & $\begin{array}{c}0.03 \\
(0.08)\end{array}$ & $\begin{array}{c}0.02 \\
(0.15)\end{array}$ \\
\hline Sweden & $\begin{array}{c}0.40 \\
(1.07)\end{array}$ & $\begin{array}{l}1.39^{* *} \\
(3.33)\end{array}$ & $\begin{array}{c}0.05 \\
(0.37)\end{array}$ \\
\hline UK & $\begin{array}{c}-1.19^{* *} \\
(2.83)\end{array}$ & $\begin{array}{l}2.65^{* *} \\
(6.35)\end{array}$ & $\begin{array}{l}-0.19 \\
(1.58)\end{array}$ \\
\hline USA & $\begin{array}{l}-0.58^{*} \\
(1.27)\end{array}$ & $\begin{array}{c}0.78^{*} \\
(1.82)\end{array}$ & $\begin{array}{l}-0.14 \\
(0.84)\end{array}$ \\
\hline
\end{tabular}


Table 5: Correlation Coefficients

Long Term Interest Rate - GDP growth - 1960-97

\begin{tabular}{|c|c|c|c|}
\hline & $\frac{\operatorname{Cov}\left(y_{t+1} i_{t}\right)}{\operatorname{Var}\left(i_{t}\right)}$ & $\frac{\operatorname{Cov}\left(\pi_{t+1} i_{t}\right)}{\operatorname{Var}\left(i_{t}\right)}$ & $\frac{\operatorname{Cov}\left(y_{t+1} \pi_{t+1}\right)}{\operatorname{Var}\left(\pi_{t+1}\right)}$ \\
\hline Austria & $\begin{array}{c}-0.86^{*} \\
(1.67)\end{array}$ & $\begin{array}{c}0.42 \\
(1.05)\end{array}$ & $\begin{array}{l}-0.03 \\
(0.12)\end{array}$ \\
\hline Belgium & $\begin{array}{c}-0.76^{* *} \\
(2.41)\end{array}$ & $\begin{array}{l}1.21^{* *} \\
(3.58)\end{array}$ & $\begin{array}{c}-0.16 \\
(1.13)\end{array}$ \\
\hline Denmark & $\begin{array}{c}-0.68^{* *} \\
(4.03)\end{array}$ & $\begin{array}{l}0.69^{* *} \\
(3.46)\end{array}$ & $\begin{array}{c}-0.52^{* *} \\
(4.26)\end{array}$ \\
\hline Finland & $\begin{array}{c}-1.12^{* *} \\
(2.71)\end{array}$ & $\begin{array}{c}0.34 \\
(0.65)\end{array}$ & $\begin{array}{c}-0.13 \\
(0.92)\end{array}$ \\
\hline France & $\begin{array}{c}-0.57^{* *} \\
(2.49) \\
\end{array}$ & $\begin{array}{l}0.97^{* *} \\
(3.07) \\
\end{array}$ & $\begin{array}{c}-0.22^{* *} \\
(2.03) \\
\end{array}$ \\
\hline Germany & $\begin{array}{c}-0.98^{* *} \\
(2.28)\end{array}$ & $\begin{array}{l}1.09^{* *} \\
(4.46)\end{array}$ & $\begin{array}{l}-0.14 \\
(0.54)\end{array}$ \\
\hline Ireland & $\begin{array}{c}-0.33 \\
(0.94)\end{array}$ & $\begin{array}{l}1.98^{* *} \\
(4.79)\end{array}$ & $\begin{array}{l}-0.07 \\
(0.64)\end{array}$ \\
\hline Italy & $\begin{array}{c}-0.87^{* *} \\
(4.39)\end{array}$ & $\begin{array}{c}0.61 \\
(1.52)\end{array}$ & $\begin{array}{c}-0.10 \\
(1.01)\end{array}$ \\
\hline Japan & $\begin{array}{l}-0.48 \\
(0.78) \\
\end{array}$ & $\begin{array}{l}1.51^{*} \\
(1.78) \\
\end{array}$ & $\begin{array}{c}-0.29^{* *} \\
(2.42) \\
\end{array}$ \\
\hline Netherlands & $\begin{array}{c}-0.98^{* *} \\
(3.65) \\
\end{array}$ & $\begin{array}{l}0.93^{* *} \\
(2.95) \\
\end{array}$ & $\begin{array}{l}-0.05 \\
(0.33) \\
\end{array}$ \\
\hline Portugal & $\begin{array}{c}-0.46 \\
(1.63)\end{array}$ & $\begin{array}{c}0.76^{*} \\
(1.78)\end{array}$ & $\begin{array}{l}-0.20^{*} \\
(1.80)\end{array}$ \\
\hline Spain & $\begin{array}{l}-0.39 \\
(1.37)\end{array}$ & $\begin{array}{l}-0.11 \\
(0.25)\end{array}$ & $\begin{array}{l}-0.05 \\
(0.44)\end{array}$ \\
\hline Sweden & $\begin{array}{l}-0.25 \\
(0.88)\end{array}$ & $\begin{array}{l}1.30^{* *} \\
(3.21)\end{array}$ & $\begin{array}{l}-0.19 \\
(0.86)\end{array}$ \\
\hline$\overline{\mathrm{UK}}$ & $\begin{array}{c}-1.21^{* *} \\
(4.10)\end{array}$ & $\begin{array}{l}1.99^{* *} \\
(3.94)\end{array}$ & $\begin{array}{c}-0.22^{* *} \\
(2.43)\end{array}$ \\
\hline USA & $\begin{array}{c}-0.82^{*} \\
(2.56)\end{array}$ & $\begin{array}{c}0.47 \\
(1.19)\end{array}$ & $\begin{array}{c}-0.27^{*} \\
(1.97)\end{array}$ \\
\hline
\end{tabular}

